ISSN 1420-3049

www.mdpi.com/journal/molecules

Review

\title{
Cherry Antioxidants: From Farm to Table
}

\section{Gianna Ferretti $^{1}{ }^{1 *}$, Tiziana Bacchetti ${ }^{1}$, Alberto Belleggia ${ }^{2}$ and Davide Neri ${ }^{2}$}

1 Department of Biochemistry, Biology and Genetic - Polytechnic University of Marche, via Ranieri 65, 60100, Ancona, Italy; E-Mail: t.bacchetti@univpm.it (T.B.)

2 SAPROV - Environment and Crop Sciences Department, Polytechnic University of Marche, 60131 Ancona, Italy; E-Mails: d.neri@univpm.it (D.N.); albertbelleg@gmail.com (A.B.)

* Author to whom correspondence should be addressed; E-Mail: g.ferretti@univpm.it; Tel.: +39-071 2204968; Fax: +39-071-2204398.

Received: 10 August 2010; in revised form: 29 September 2010 / Accepted: 11 October 2010 / Published: 12 October 2010

\begin{abstract}
The dietary consumption of fruits and vegetables is associated with a lower incidence of degenerative diseases such as cardiovascular disease and certain types of cancers. Most recent interest has focused on the bioactive phenolic compounds found in vegetable products. Sweet and sour cherries contain several antioxidants and polyphenols that possess many biological activities, such as antioxidant, anticancer and antiinflammation properties. The review describes the effect of environment and other factors (such as production, handling and storage) on the nutritional properties of cherries, with particular attention to polyphenol compounds. Moreover the health benefits of cherries and their polyphenols against human diseases such as heart disease, cancers, diabetes are reviewed.
\end{abstract}

Keywords: sour cherry; sweet cherry; antioxidants; polyphenols; oxidative stress; bioactive compounds; bioavailability; chronic diseases

\section{Introduction}

Several studies have demonstrated that fruits and vegetables exert a protective effect against the development of human diseases such as cardiovascular disease, diabetes and cancer [1-4]. It has been hypothesized that the protective role could be due to the various nutrients they contain such as fiber, vitamins and phytonutrients. Phenolics are secondary plant metabolites characterized by having at least 
one aromatic ring with one or more hydroxyl groups attached. The nature and the distribution of phenolics differ by plant tissue, with many of the phenolics synthesized from carbohydrates via the shikimate and phenyl propanoid pathways (Figure 1). Phenolics range from simple, low molecular weight, single-aromatic ring compounds to the large complex tannins. They can be classified by the number and arrangements of the carbon atoms. These molecules are generally involved in defense against ultraviolet radiation or aggression by plant pathogens. Polyphenols generally occur as glycosylated derivatives in plants, although conjugation with inorganic acid and malonylation are also known. Several studies in animal models and in human subjects have demonstrated that phenols are bioavailable and exert a protective role against oxidative stress and free radical damages $[5,6]$.

Figure 1. Synthesis of phytonutrients in plant cells. PEP,phosphoenolpyruvate; IPP,isopenthenylpyrophosphate; GPP, geranylpyrophosphate.

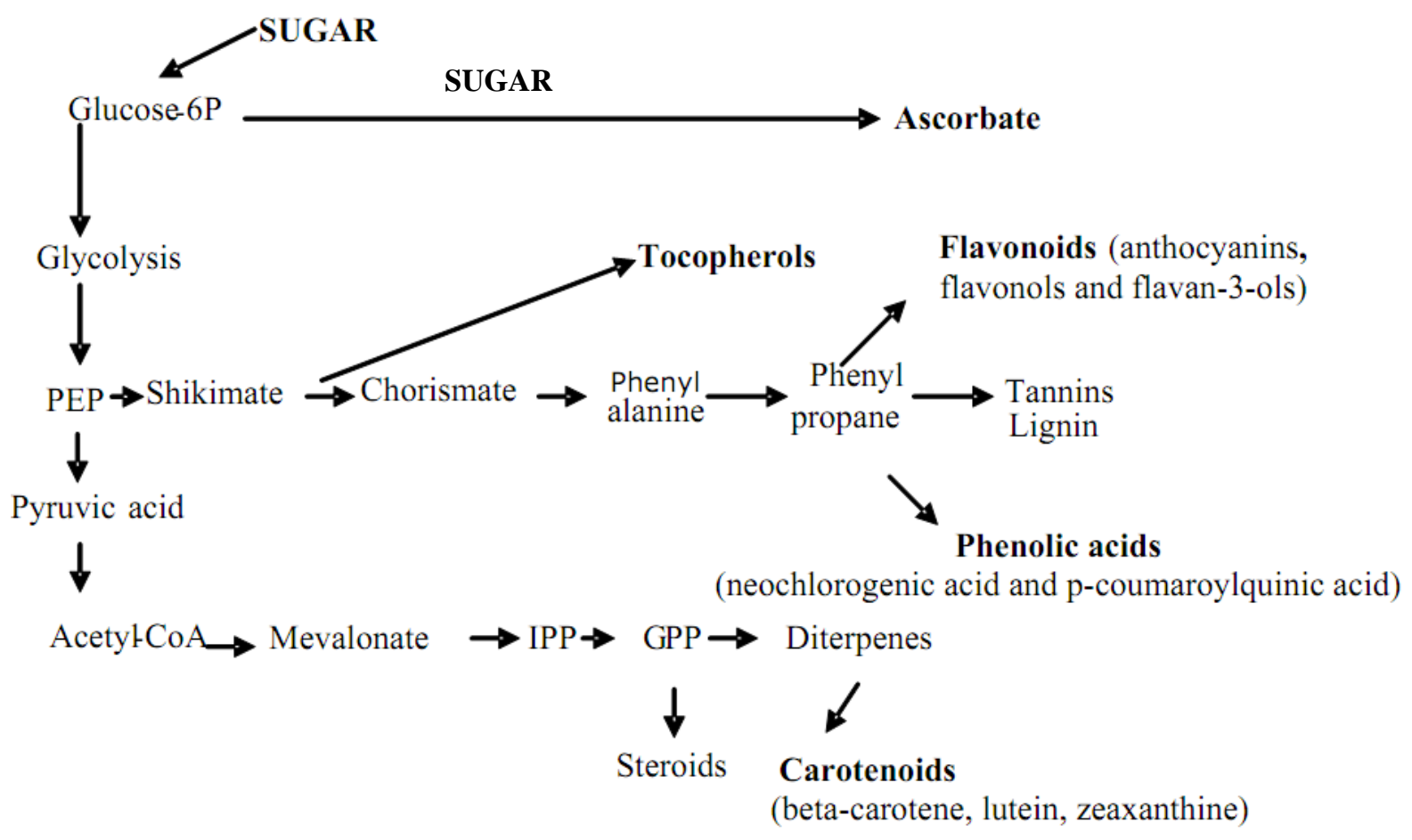

Oxidative damage, triggered by free radicals, causes structural and functional alterations of cell macromolecules and is involved in the molecular mechanisms of chronic human diseases $[7,8]$. Antioxidants have the ability to scavenge or to neutralize free radicals, or are necessary to enable other molecules to perform such a function [8]. Several studies demonstrated that cherries contain several nutrients such as phytonutrients and antioxidants. Aim of this review was to describe the effect of environment and other factors (such as production, handling and storage) on nutritional properties of cherries with particular attention to polyphenol compounds. Moreover the health benefits of cherries and their polyphenols against human diseases such as heart disease, cancers, diabetes will be reviewed.

\section{Nutritional Properties of Sweet and Sour Cherries}

Cherries (Prunus spp.) are the smallest members of the stone fruit family: Rosaceae, genus: Prunus; subgenera: Cerasus and Padus. They comprise over a hundred species, classified in pomological terms into two distinct groups based on the type of inflorescence (corymb or racemosa). 
Among the most important species with the corymb inflorescence, belonging to the subgenus Cerasus, Prunus avium L., know as "sweet cherry", and Prunus cerasus L., known as "sour cherry or tart cherry" are the most important. The sour cherry varieties are divided in three main groups depending on tree habit and fruit characteristics: Kentish cherries, morellos and marasca.

The main characteristics related to cherry fruit quality are colour, sweetness, sourness, and firmness. Sweetness in the cherry fruit is mainly due to glucose and fructose, while sourness is primarily due to the presence of organic acid (malic acid) $[9,10]$. The acceptance by consumers seems to be dependent on the ratio between sugar and acid concentrations [11]. Sweet cherries are characterized by a higher content of simple sugar $(13 \mathrm{~g} / 100 \mathrm{~g})$ with respect to sour cherries ( $8 \mathrm{~g} / 100 \mathrm{~g})$. Cherries contain both hydrosoluble (C,B) and liposoluble (A, E and K) vitamins and some carotenoids, in particular beta-carotene, and to a lower extent lutein and zeaxantine (Table 1). As summarized in Table 1, sour cherries are characterized by an higher content of vitamin A and betacarotene. Cherries contain also minerals such as calcium $(14 \mathrm{mg} / 100 \mathrm{~g})$, magnesium $(10 \mathrm{mg} / 100 \mathrm{~g})$, phosphorous $(20 \mathrm{mg} / 100 \mathrm{~g})$ and potassium $(200 \mathrm{mg} / 100 \mathrm{~g})$. In two tart cherry cultivars Burkhardt et al. demonstrated the presence of melatonin $(13.46 \pm 1.10 \mathrm{ng} / \mathrm{g}$ and $2.06 \pm 0.17 \mathrm{ng} / \mathrm{g}$ in Balaton and Montmorency, respectively) [12]. As shown in Table 1, sour cherries contain a higher level of total phenolics than sweet cherries.

Table 1. Phytonutrients in sweet and sour cherries (in $100 \mathrm{~g}$ ).

\begin{tabular}{|l|c|c|}
\cline { 2 - 3 } \multicolumn{1}{c|}{} & Sweet cherries & Sour cherries \\
\hline Vitamin C & $7 \mathrm{mg}$ & $10 \mathrm{mg}$ \\
Niacin & $0.2 \mathrm{mg}$ & $0.4 \mathrm{mg}$ \\
Pantothenic Acid & $0.2 \mathrm{mg}$ & $0.1 \mathrm{mg}$ \\
Vitamin A & $64 \mathrm{IU}$ & $1283 \mathrm{IU}$ \\
Vitamin E (Alpha Tocopherol) & $0.1 \mathrm{mg}$ & $0.1 \mathrm{mg}$ \\
Vitamin K & $2.1 \mu \mathrm{g}$ & $2.1 \mu \mathrm{g}$ \\
Beta Carotene & $38 \mu \mathrm{g}$ & $770 \mu \mathrm{g}$ \\
Lutein+Zeaxanthin & $85 \mu \mathrm{g}$ & $85 \mu \mathrm{g}$ \\
Total Phenols & $109.8 \mathrm{mg}$ & $228.9 \mathrm{mg}$ \\
\hline
\end{tabular}

\subsection{Polyphenols in cherries}

In cherry, as in other red fruits, the ripening process is related to a change from the initial green color to red, with accumulation of polyphenolic compounds, anthocyanins and degradation of chlorophyll. Phenolic compounds are concentrated in the skin and contribute to sensory and organoleptic qualities of fruits, such as taste and astringency. Furthermore, it has been demonstrated that they are bioactive compounds. The phenols contained in sour and sweet cherries have been characterized [13]. Cyanidin 3glucoside, cyanidin 3-rutinoside, cyanidin 3-sophoroside, pelargonidin 3-glucoside, pelargonidin 3rutinoside, 3-glucoside, and peonidin 3-rutinoside have been identified in sweet and sour cherries [14-18].

Among phenolic acids, hydroxycinnamates (neochlorogenic acid and p-coumaroylquinic acid) have been quantified either in sweet and sour cherries. Flavonols and flavan-3-ols such as catechin, epicatechin, quercetin 3-glucoside, quercetin 3-rutinoside, and kaempferol 3-rutinoside were also 
found in sweet and sour cherries $[15,16]$. The higher levels of total phenolics in sour cherries have been attributed to higher concentrations of anthocyanins and hydroxycinnamic acids [19] (Table 2).

As summarized in Table 2, different cultivars of sweet and sour cherries show a high variability of phenol compound levels. Total anthocyanins of sweet cherries are between 30 (cv. Black Gold) and 79(cv. Cristalina) mg cyanidin-3-glucoside equivalents (CGE)/100 g, whereas total anthocyanins of sour cherries were between 45(cv. Balaton) and 109 (cv. Sumadinka) mg CGE/100g [13,19].

Table 2. Total anthocyanins and total phenols in different cultivars of sweet or sour cherries ${ }^{a}$ from Serrano et al (2009); ${ }^{b}$ from Kim DO et al. (2005); GAE, gallic acid equivalent; CGE, cyanidin-3-glucoside equivalents.

\begin{tabular}{lcc}
\hline Cultivar & $\begin{array}{c}\text { Total phenols (mg } \\
\text { GAE/100g fresh cherries ) }\end{array}$ & $\begin{array}{c}\text { Total anthocyanins } \\
\text { (CGE/100g fresh cherries) }\end{array}$ \\
\hline sweet Brooks $^{\mathbf{a}}$ & $60 \pm 13$ & $10 \pm 2$ \\
sweet Newstar $^{\mathbf{a}}$ & $75 \pm 14$ & $20 \pm 5$ \\
sweet Black Gold $^{\mathbf{b}}$ & $92 \pm 12$ & $30 \pm 9$ \\
sweet Hedelfingen $^{\mathbf{b}}$ & $96 \pm 20$ & $40 \pm 7$ \\
sweet Regina $^{\mathbf{b}}$ & $104 \pm 6$ & $41 \pm 2$ \\
sweet Hartland $^{\mathbf{b}}$ & $147 \pm 19$ & $76 \pm 12$ \\
sweet Cristalina $^{\mathbf{a}}$ & $155 \pm 20$ & $79 \pm 5$ \\
sour Balaton $^{\mathbf{b}}$ & $254.1 \pm 6.0$ & $45 \pm 2.3$ \\
sour Danube $^{\mathbf{b}}$ & $162 \pm 1$ & $65 \pm 3$ \\
sour Schattenmorelle $^{\mathbf{b}}$ & $295 \pm 34$ & $72 \pm 6$ \\
sour Sumadinka $^{\mathbf{b}}$ & $312 \pm 8$ & $109 \pm 6$ \\
\hline
\end{tabular}

2.2. Effect of pre-harvest and post harvest conditions on cherry nutritional properties

Genetic and environmental factors modulate the composition and concentration of macronutrients, micronutrient and phytonutrients in plant foods [16,20,21].

\subsubsection{Effect of pre-harvest factors}

Pre-harvest factors and temperature, light intensity, fruit crops maturity may affect the content and stability of phytochemicals and the nutritional value in cherries. Light intensity increases levels of ascorbic acid and different growing temperatures (day/night) also affect total phenolic content. High temperature growing conditions $\left(25 / 30{ }^{\circ} \mathrm{C}\right)$ significantly enhance anthocyanin and total phenolic content [22]. Also soil types, composts, mulching and fertilization influence the water and nutrient supply to the plant and can affect the nutritional composition of the harvested fruit.

Actually, in cool growing areas interest is increasing in growing cherries under plasticulture systems to prevent cherry cracking and to favour harvest operations. This cultivation system can influence canopy and soil temperature, quantity and quality of transmitted, reflected or absorbed light, with a possible difference in fruit growth, development, quality or carbohydrate metabolism. For example, in strawberry black plastic mulching consistently resulted in higher flavonoids, anthocyanin and total phenolic content compared to the traditional matted row culture system [22]. 
Actually in all cherry growing regions different rootstock are used for many reasons related to climate, environment, field and orchard training. 'PiKu 1' and 'Weiroot 13' rootstocks gave fruits of Lapins cultivar with significantly higher phenolic acid and flavonol content [23]. Higher amounts of phenols in sweet cherry fruits grown on heterogenic graft combinations might be attributed to the adjustment of the metabolism to genetically different between rootstocks and varieties, which causes higher amounts of metabolic stress [24]. Trees of different vigor can produce sweet cherry fruits with different phenolic acid and flavonol content. Wild growing sweet cherry genotypes have different nutritional properties and are relatively higher in blackish skin colored fruits than in light skin colored ones [25].

\subsubsection{Post-harvest factors}

Post harvest factors such as transport and storage can also influence phytochemical composition of food crops. In some cases, an increase in phenolic content has been observed in the days following fruit purchase and they are generally stable during storage [26]. For all cultivars and maturity stages, during postharvest storage the ripening process advances, acidity decreases, and color intensity increases as well as anthocyanins. During cold storage and subsequent shelf-life, a general increase (over $40-60 \%$ on average) in phenolic compound is observed [27,28].

Modern technology could indirectly increase the nutritional value of fruits through the delay of the softening process so that fruits could be harvested at a later, more mature stage, when more of the phyto-compounds have been bio-synthesized [22].

\subsubsection{Cherries processed products}

Sweet cherries (Prunus avium L.) are mainly consumed as fresh fruit. Processed cherries are available all year-round: dry (with or without sugar), frozen, as juice or concentrate, in IQF (individually quick frozen) powder, and canned [15]. During canning, approximately half the anthocyanins and phenolics leach from the fruits into the syrup with little total loss. Spent cherry brine contains substantial anthocyanins and phenolics [15]. Recently we demonstrated that the levels of total phenolic compounds are higher in fully ripen sour cherries when compared to early ripen fruits (unpublished results). Similar results have been reported also in different cultivars of sweet cherries [28].

Frozen sour cherries derived from Balaton and Montmorency have the highest levels for both anthocyanins and total phenolics and products processed with sugar (15\% of total fresh weight) show lower concentrations for both anthocyanins and phenolic than dry products [29]. Heat processing does not result in a loss of total anthocyanins and total phenolics when the values for syrup and cherries were combined [15].

\section{Cherry Phenols Bioavailability and Physiological Roles}

Bioavailability of dietary polyphenols and tissue concentrations have been previously investigated. It has been demonstrated that bioavailability varies widely among polyphenols and, for some of compounds, among dietary sources, depending on the forms they contain [30,31]. Furthermore, fruit 
maturity state could also modulate bioavailability as demonstrated by Fazzari et al. [32], using sweet cherries. Food polyphenols are mainly found in glycosylated forms, and glycosylation influences absorption [31]. In fact the aglycones can be absorbed from the small intestine, while polyphenols present in food in the form of esters, glycosides, or polymers must be hydrolyzed by intestinal enzymes or by the colonic microflora before they can be absorbed. After absorption, phenols are conjugated in the small intestine and later in the liver. This process is highly efficient and mainly includes methylation, sulfation and glucuronidation. Circulating polyphenols are conjugated derivatives that are transported bound to albumin to peripheral tissues where they can exert physiological roles. Finally, they are eliminated chiefly in urine and bile [31].

Polyphenols have been quantified in several tissues reaching a concentration ranging from 30 to $3,000 \mathrm{ng}$ aglycone equivalents/g tissue, in relation to the dietary intake [31,33]. The plasma kinetics differ among polyphenol classes, with higher concentrations reached after about $1.5 \mathrm{~h}$ or $5.5 \mathrm{~h}$, depending on the site of intestinal absorption [34]. Plasma concentration reached after phenol consumption varies highly according to the nature of phenols and food source with values ranging 0.5-1.6 $\mu \mathrm{M}$ [31]. Human genetic differences could lead to differences in absorption and metabolic clearance between individuals, in addition to differences in intestinal microorganism populations [35]. As far as concerns tannins, they are very poorly absorbed and may exert only local activity in the gastrointestinal tract [31].

\subsection{Bioactivity of phenolic compounds from sour and sweet cherry}

Cherries contain several phenolic compounds whose biological activities have been recently investigated in different experimental models. Antioxidant, anti-inflammatory and anticancer properties have been demonstrated and the molecular mechanisms are summarized in Figure 2.

\subsubsection{Antioxidant activity}

The antioxidant capacity of extracts from cherries has been widely investigated using different methodological approaches. Using an ORAC (oxygen radical absorbance capacity) assay, it has been reported that the antioxidant capacity ranges from 1,145 to 1,916 $\mu$ mol Trolox equivalents (TE)/100 $\mathrm{g}$ in sour cherries (Amarena Mattarello, Visciola Ninno and Visciola Sannicandro) [36]. It has to be stressed that the values found in sour cherry fruits are comparable to those found in some berry fruits, for example, strawberry, and are higher than in apple and kiwi fruit [37].

The antioxidant activity of cherry extracts has been studied also in different biological samples and Tsuda et al. [38,39] demonstrated, among the anthocyanins tested, cyanidin 3-glucoside, showed stronger antioxidant activity. Using liposomes as model membranes, it has been reported that anthocyanins, cyanidin and hydroxycinnamates isolated from tart or sweet cherries are more active compared to those of other berries (such as blackberries, red raspberries, blueberries or strawberries) [40]. Furthermore, extracts of sweet cherries are able to inhibit copper triggered low density lipoproteins (LDL) oxidation, an atherogenic modification of this lipoprotein class [40]. The antioxidant activity of cherry phenolics was confirmed using neuronal PC 12 cells exposed to oxidative stress [41]. 
Cherries show antioxidant effects also in vivo (Figure 2). An increased activity of the antioxidant enzymes SOD (liver, blood) and Gpx (liver) and a decrease of lipid peroxidation were observed in animal model fed with sour cherry juices obtained from an autochthonous cultivar (Prunus cerasus cv. Maraska) [42]. Studies in human subjects, reported that the consumption of $280 \mathrm{~g}$ of cherries (about 45 sweet Bing cherries) increased plasma lipophilic antioxidant capacity [43,44]. Moreover, in a doubleblind, placebo-controlled crossover design, tart cherry juice intake (240 mL twice daily for $14 \mathrm{~d})$ was associated with a decrease of $\mathrm{F}(2)$-isoprostane levels, a marker of oxidative damage, in response to forearm ischemia-reperfusion. In the same subjects a decrease of urinary excretion of markers of oxidized nucleic acids (8-hydroxy-2'-deoxyguanosine, 8-hydroxyguanosine) was demonstrated [45]. In addition to anthocyanins also phenolic acids could contribute to antioxidant activity of cherries [40].

Figure 2. Protective effects exerted by cherry phenols and implication in chronic diseases.

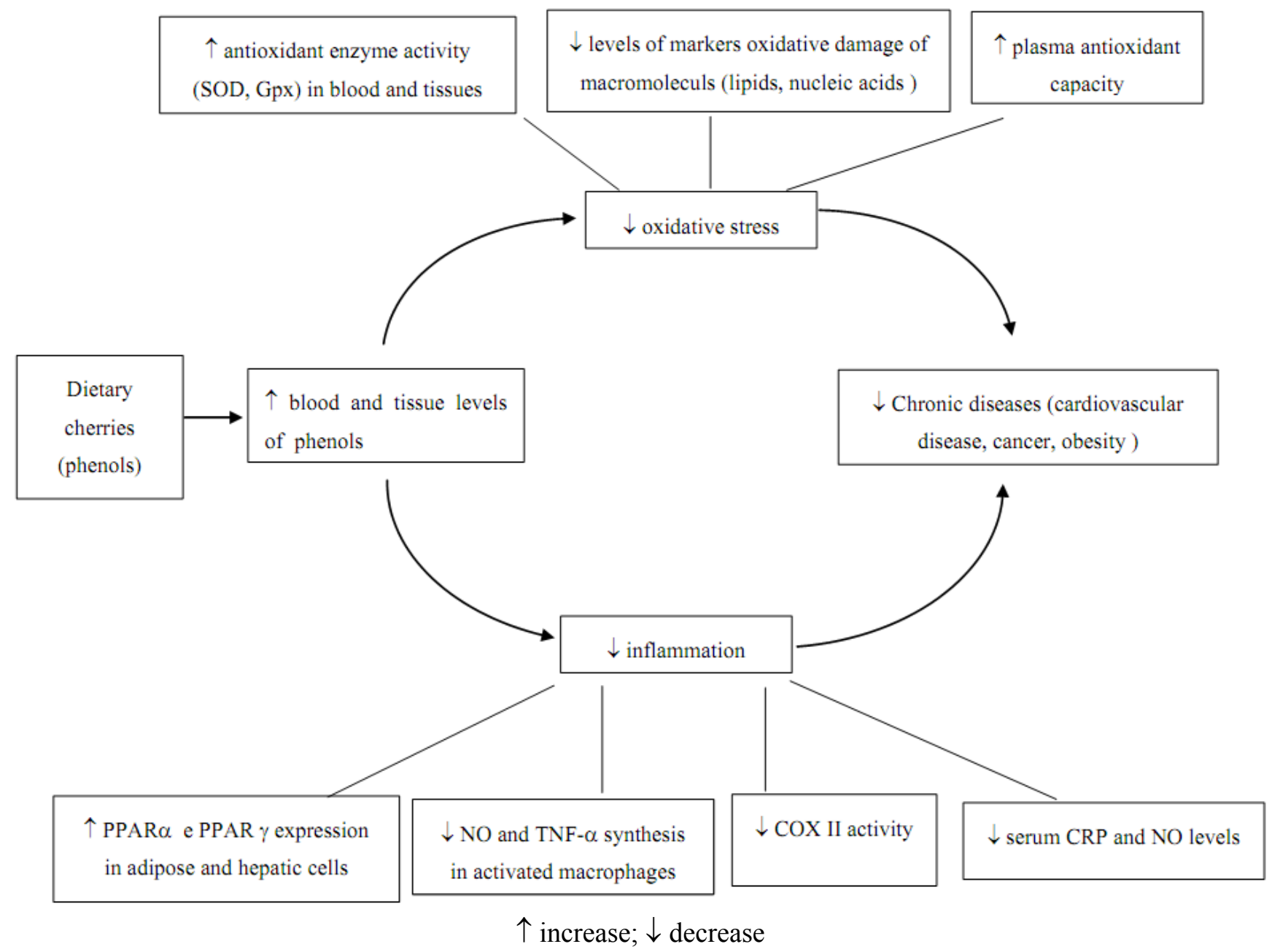

\subsubsection{Anti inflammatory effect}

Several studies have demonstrated that cherry intake inhibits inflammatory pathways. Kelley et al [46] have shown a decrease of blood levels of C-reactive protein (CRP) and nitric oxide (NO) in healthy subjects after intake of sweet cherries $(280 \mathrm{~g} / \mathrm{die})$ for 28 days [46]. These results are in agreement with other studies [44]. Elevated levels of serum CRP is one of the most important indicators of inflammation and it is a significant risk factor for cardiovascular disease (CVD) [47]. The 
decrease in plasma CRP levels after cherry intake suggests a reduction in inflammation that may affect the risk for cardiovascular diseases. Also the increased production of NO and their reaction product peroxynitrite (ONOO-) contribute to oxidative stress, tissue injury and an increase of their plasma concentrations are implicated in a variety of rheumatic diseases, including systemic lupus erythematosus, rheumatoid arthritis and osteoarthritis $[48,49]$. It has been suggested that the decrease in plasma NO level probably results from inhibition of the enzyme nitric oxide synthase-inducible (iNOS) activity [46]. Studies in vitro have demonstrated that anthocyanins are able to inhibit nitric oxide (NO) production and other pro-inflammatory factors such tumor necrosis factor-alpha (TNF- $\alpha$ ) in activated macrophages [50,51]. Therefore, it has been suggested that the anti-inflammatory properties of cherries could be mainly related to anthocyanins.

Studies in vitro and in vivo have demonstrated that anti-inflammatory properties of cherry phenols could also due to inhibition of the activity of the cyclooxygenase II (COX II) [42,52,53]. COXs are pro-inflammatory enzymes that play an important role in processes such as inflammation, carcinogenesis, apoptosis, cell proliferation and angiogenesis. It has to be stressed that the cyclooxygenase inhibitory activities of cherry anthocyanins are comparable to those of ibuprofen and naproxen at $10 \mu \mathrm{M}$ concentrations [52,53].

The inhibitory effect of inflammatory pathways has been hypothesized to be the main molecular mechanism to explain the relationship between the consumption of cherries or cherry products and the alleviation of arthritic pain and gout [54-58].

Obesity is associated with inflammation. Using model animals (Zucker fatty rat model of obesity and metabolic syndrome and Dahl Salt-Sensitive rat) it has been demonstrated that tart cherry-enriched diets reduce plasma and tissue inflammation. In fact it has been reported that cherry intake for 90 days significantly reduced the levels of proinflammatory molecules in plasma (interleukin-6, TNF- $\alpha$ ) and the activity nuclear factor kappa and increases peroxisome proliferator-activated receptors (PPARs) in abdominal fat and in hepatic tissues. These modifications were associated with a decrease of levels of serum glucose, triglycerides and cholesterol $[59,60]$.

\subsection{Anticancer properties}

Studies in vitro using several cell culture systems including colon, endothelial, liver, breast and leukemic cells and keratinocytes have demonstrated that anthocyanins exhibit multiple anticarcinogenic effects [61]. Potential cancer chemopreventive activities of anthocyanins revealed from in vitro studies include also their ability to stimulate the expression of Phase II detoxification enzymes (glutathione reductase, glutathione peroxidase and $\mathrm{NAD}(\mathrm{P}) \mathrm{H}$ : quinone reductase) and to inhibit mutagenesis by environmental toxins and carcinogens. Moreover, anthocyanins are able to induce cellular apoptosis and differentiation and to reduce cellular proliferation by modulating different signal transduction pathways (PI3K/Akt, ERK, JNK, and MAPK pathways) [61].

As far as concerns cherry anthocyanins, studies in vitro have demonstrated that they are able to reduce proliferation of human colon cancer cells in culture [62]. Moreover, using APC(Min) mice, a model for human colon cancer, it has shown that tart cherry extract intake $(375-3,000 \mathrm{mg} / \mathrm{kg}$ diet $)$ inhibit tumor development $[62,63]$. 


\section{Conclusions}

Several studies have shown that the prevention of cancer, cardiovascular disease and obesity are beneficial health effects attributable to phytocompounds found in fruits and vegetables. The significant decrease of markers of inflammation and oxidative stress afforded by cherries and derivates may have implications for the management of clinical pathologies associated with high levels of inflammation and oxidative stress and suggests that their consumption may have the potential to reduce cardiovascular or chronic diseases in humans (Figure 2). Cherries contain higher amounts of phytocompounds, in particular of phenols when compared to several other fruits, but with high variability among different cultivars, the highest phenols contents being in the sour cherries. Not only genetics, but also environmental factors and cultivation techniques may modulate the composition and concentration of macronutrients, micronutrient and phytonutrients in the cherries. In particular preharvest day and night temperature, light intensity, and fruits maturity may affect the content and stability of phytochemicals. Cherry orchard management and fertilization are also important and may strongly affect tree vigor and finally fruit phenolic acid and flavonol content. Modern technology could indirectly increase the nutritional value of fruits, protecting the fruits from the cracking and delaying the softening process so that fruits could be harvested at a later, more mature stage, with higher phytocompounds content. The type of consumption is also important: sweet cherries are mainly consumed as fresh fruit and tart cherries are generally processed. It is worth noting that modern processing techniques do not result in a loss of total anthocyanins and total phenolics, thus allowing having an allaround-year consumption of healthy delicious cherry fruits.

\section{References}

1. Hu, F.B. Plant-based foods and prevention of cardiovascular disease: an overview. Am. J. Clin. Nutr. 2003, 78, 544S-551S.

2. He, F.J.; Nowson, C.A.; Lucas, M.; MacGregor, G.A. Increased consumption of fruit and vegetables is related to a reduced risk of coronary heart disease: Meta-analysis of cohort studies. J. Hum. Hypertens. 2007, 21, 717-728.

3. Riboli, E.; Norat, T. Epidemiologic evidence of the protective effect of fruit and vegetables on cancer risk. Am. J. Clin. Nutr. 2003, 78 (3 Suppl.), 559S-569S.

4. Steinmetz, K.A.; Potter, J.D. Vegetables, fruit, and cancer prevention: A review. J. Am. Diet. Assoc. 1996, 96, 1027-1039.

5. Prior, R.L. Fruits and vegetables in the prevention of cellular oxidative damage. Am. J. Clin. Nutr. 2003, 78, 570-578.

6. Szajdek, A.; Borowska, E.J. Bioactive compounds and health-promoting properties of berry fruits: A review. Plant Foods Hum. Nutr. 2008, 63, 147-156.

7. Benzie, I.F. Lipid peroxidation: A review of causes, consequences, measurement and dietary influences. Int. J. Food Sci. Nutr. 1996, 47, 233-261.

8. Machlin, L.J.; Bendich, A. Free radical tissue damage: Protective role of antioxidant nutrients FASEB J. 1987, 1, 441-445. 
9. Bernalte, M.J.; Sabio, E.; Herna'ndez, M.T.; Gervasini, C. Influence of storage delay on quality of "Van" sweet cherry. PostharVest. Biol. Technol. 2003, 28, 303-312.

10. Esti, M.; Cinquante, L.; Sinesio, F.; Moneta, E.; Matteo, M. Physicochemical and sensory fruit characteristics of two sweet cherry cultivars after cool storage. Food Chem. 2002, 76, 399-405.

11. Crisosto, C.H.; Crisosto, G.M.; Metheney, P. Consumer acceptance of "Brooks" and "Bing" cherries is mainly dependent on fruit SSC and visual skin color. Postharvest Biol. Technol. 2003, 28, 159-167.

12. Burkhardt, S.; Tan, D.X.; Manchester, L.C.; Hardeland, R.; Reiter, R.J. Detection and quantification of the antioxidant melatonin in Montmorency and Balaton tart cherries (Prunus cerasus). J. Agric. Food Chem. 2001, 49, 4898-4902.

13. Serrano, M.; Guille'n, F.; Martı'nez-Romero, D.; Castillo, S.; Valero, D. Chemical constituents and antioxidant activity of sweet cherry at different ripening stages. J. Agric. Food Chem. 2005, 53, 2741-2745.

14. Mozetic $`$, B.; Trebše, P.; Hribar, J. Determination and quantitation of anthocyanins and hydroxycinnamic acids in different cultivars of sweet cherries (Prunus avium L.) from Nova Gorica Region (Slovenia). Food Technol. Biotechnol. 2002, 40, 207-212.

15. Chaovanalikit, A.; Wrolstad, R.E. Total anthocyanins and total phenolics of fresh and processed cherries and their antioxidant properties. J. Food Sci. 2004, 69, FST67-FST72.

16. Gao, L.; Mazza, G. Characterization, quantitation, and distribution of anthocyanins and colorless phenolics in sweet cherries. J. Agric. Food Chem. 1995, 43, 343-346.

17. Chandra, A.; Nair, M.G.; Iezzoni, A. Evaluation and characterization of the anthocyanin pigments in tart cherries (Prunus cerasus L.). J. Agric. Food Chem. 1992, 40, 967-969.

18. Chandra, A.; Rana, J.; Li, Y. Separation, identification, quantification, and method validation of anthocyanins in botanical supplement raw materials by HPLC and HPLC-MS. J. Agric. Food Chem. 2001, 49, 3515-3521.

19. Kim, D.; Heo, H.J.; Kim, Y.J.; Yang, H.S.; Lee, C.Y. Sweet and Sour Cherry Phenolics and Their Protective Effects on Neuronal Cells. J. Agric. Food Chem. 2005, 53, 9921-9927.

20. Tomás-Barberán, F.A.; Espín, J.C. Phenolic compounds and related enzymes as determinants of quality in fruits and vegetables. J. Sci. Food Agric. 2001, 81, 853-876.

21. Kim, D.O.; Padilla-Zakour, O.I. Jam processing effect on phenolics and antioxidant capacity in anthocyanin-rich fruits: Cherry, plum, and raspberry. J. Food Sci. 2004, 69, S395-S400.

22. Wang, S.Y. Effect of Pre-harvest Conditions on Antioxidant Capacity in Fruits. Acta Hort. 2006, 712.

23. Jakobek, L.; Seruga, M.; Voca, S.; Sindrak, Z.; Dobricevic, N. Flavonol and phenolic acid composition of sweet cherries (cv. Lapins) produced on six different vegetative rootstocks. Sci. Hort-Amsterdam 2009, 123, 23-28.

24. Usenik, V.; Štampar, F. Seasonal changes in polyphenols of 'Lapins' sweet cherry grafted on different rootstocks. Acta Hortic. 2005, 667, 239-246.

25. Karlidag, H.; Ercisli, S.; Sengul, M.; Tosun, M. Physico-chemical diversity in fruits of wildgrowing sweet cherries (Prunus avium L.). Biotechnol. Biotechnol. Eq. 2009, 23, 3. 
26. Kevers, C.; Falkowski, M.; Tabart, J.; Defraigne, J.O.; Dommes, J.; Pincemail, J. Evolution of Antioxidant Capacity during Storage of Selected Fruits and Vegetables. J. Agric. Food Chem. 2007, 55, 8596-8603.

27. Serrano, M.; Diaz-Mula, H.M.; Zapata, P.J.; Castillo, S.; Guillén, F.; Martinez-Romero, D.; Valverde Juan, M.; Valero, D. Maturity Stage at Harvest Determines the Fruit Quality and Antioxidant Potential after Storage of Sweet Cherry Cultivars J. Agric. Food Chem. 2009, 57, 3240-3246.

28. Gonçalves, B.; Landbo, A.K.; Knudsen, D.; Silva, A.P.; Moutinho-Pereira, J.; Rosa, E.; Meyer, A.S. Effect of Ripeness and Postharvest Storage on the Phenolic Profiles of Cherries (Prunus avium L.). J. Agric. Food Chem. 2004, 52, 523-530.

29. Kirakosyan, A.; Seymour, E.M.; Urcuyo Llanes, D.E.; Kaufman, P.B.; Bolling, S.F. Chemical profile and antioxidant capacities of tart cherry products. Food Chem. 2009, 115, 20-25.

30. Scalbert, A.; Williamson, G. Dietary Intake and Bioavailability of Polyphenols. J. Nutr. 2000, 130, 2073S-2085S.

31. Manach, C.; Scalbert, A.; Morand, C.; Rémésy, C.; Jiménez, L. Polyphenols: Food sources and bioavailability. Am. J. Clin. Nutr. 2004, 79, 727-747.

32. Fazzari, M.; Fukumoto, L.; Mazza, G.; Livrea, M.A; Tesoriere, L.; Di Marco, L. In vitro Bioavailability of Phenolic Compounds from Five Cultivars of Frozen Sweet Cherries (Prunus avium L.). J. Agric. Food Chem. 2008, 56, 3561-3568.

33. Kalt, W.; Blumberg, J.B.; McDonald, J.E.; Vinqvist-Tymchuk, M.R.; Fillmore, S.A.; Graf, B.A.; O'Leary, J.M.; Milbury, P.E. Identification of anthocyanins in the liver, eye, and brain of blueberry-fed pigs. J. Agric. Food Chem. 2008, 56, 705-712.

34. Milbury, P.E.; Vita, J.A.; Blumberg, J.B. Anthocyanins are Bioavailable in Humans following an Acute Dose of Cranberry Juice. J. Nutr. 2010, 140, 1099-1104.

35. Manach, C.; Williamson, G.; Morand, C.; Scalbert, A.; Rémésy, C. Bioavailability and bioefficacy of polyphenols in humans. I. Review of 97 bioavailability studies. Am. J. Clin. Nutr. 2005, 81, 230S-242S.

36. Blando, F.; G.erardi, C.; Nicoletti, I. Sour Cherry (Prunus cerasus L.) Anthocyanins as Ingredients for Functional Foods. J. Biomed. Biotechnol. 2004, 5, 253-258.

37. Lister, C.E.; Wilson, P.E.; Sutton, K.H.; Morrison, S.C. Understanding the health benefits of blackcurrants. Acta Hort. 2002, 585, 443-449.

38. Tsuda, T.; Watanabe, M.; Ohshima, K.; Norinobu, S.; Choi, S.W.; Kawakishi, S.; Osawa, T.; Antioxidative activity of the anthocyanin pigments cyanidin 3-O-beta-D-glucoside and cyanidin. J. Agric. Food Chem. 1994, 42, 2407-2410.

39. Tsuda, T.; Horio, F.; Kitoh, J.; Osawa, T. Protective effects of dietary cyanidin 3-O-beta-Dglucoside on liver ischemia-reperfusion injury in rats. Arch. Biochem. Biophys. 1999, 368, 361-366.

40. Heinonen, M.; Meyer, A.S.; Frankel, E.N. Antioxidant Activity of Berry Phenolics on Human Low-Density Lipoprotein and Liposome Oxidation J. Agric. Food Chem. 1998, 46, 4107-4111.

41. Kim, D.O.; Heo, H.J.; Kim, Y.J.; Yang, H.S.; Lee, C.Y. Sweet and sour cherries phenolics and their protective effects on neuronal cells. J. Agric. Food Chem. 2005, 53, 9921-9927. 
42. Sarić, A.; Sobocanec, S.; Balog, T.; Kusić, B.; Sverko, V.; Dragović-Uzelac, V.; Levaj, B.; Cosić, Z.; Macak Safranko, Z.; Marotti, T. Improved antioxidant and anti-inflammatory potential in mice consuming sour cherry juice (Prunus cerasus cv. Maraska).Plant Foods Hum. Nutr. 2009, 64, 231-237.

43. Prior, R.L.; Gu, L.; Wu, X.; Jacob, R.A.; Sotoudeh, G.; Kader, A.A.; Cook, R.A. Plasma Antioxidant Capacity Changes Following a Meal as a Measure of the Ability of a Food to Alter In vivo Antioxidant Status. J. Am. Coll. Nutr. 2007, 26, 170-181.

44. Jacob, R.A.; Spinozzi, G.M.; Simon, V.A.; Kelley, D.S.; Prior, R.L.; Hess-Pierce, B.; Kader, A.A.Consumption of cherries lowers plasma urate in healthy women. J. Nutr. 2003, 133, 1826-1829.

45. Traustadóttir, T.; Davies, S.S.; Stock, A.A.; Su, Y.; Heward, C.B.; Roberts, L.J., $2^{\text {nd }}$; Harman, S.M. Tart cherry juice decreases oxidative stress in healthy older men and women. J. Nutr. 2009, 139, 1896-1900.

46. Kelley, D.S.; Rasooly, R.; Jacob, R.A.; Kader, A.A.; Mackey, B.E. Consumption of Bing sweet cherries lowers circulating concentrations of inflammation markers in healthy men and women. $J$. Nutr. 2006, 136, 981-986.

47. Ridker, P.M. High-sensitivity C-reactive protein: potential adjunct for global risk assessment in primary prevention of cardiovascular disease. Circulation 2001, 103, 1813-1818.

48. Abramson, S.B.; Amin, A.R.; Clancy, R.M.; Attur, M. The role of nitric oxide in tissue destruction. Best Pract. Res. Clin. Rheumatol. 2001, 15, 831-845.

49. Onur, O.; Akinci, A.S.; Akbiyik, F.; Unsal, I. Elevated levels of nitrate in rheumatoid arthritis. Rheumatol. Int. 2001, 20, 154-158.

50. Wang, J.; Mazza, G. Inhibitory effects of anthocyanins and other phenolic compounds on nitric oxide production in LPS/IFN-gamma-activated RAW 264.7 macrophages. J. Agric. Food Chem. 2002, 50, 850-857.

51. Wang, J.; Mazza, G. Effects of anthocyanins and other phenolic compounds on the production of tumor necrosis factor alpha in LPS/IFN-gamma-activated RAW 264.7 macrophages. J. Agric. Food Chem. 2002, 50, 4183-4189.

52. Wang, H.; Nair, M.G.; Strasburg, G.M. Antioxidant and antiinflammatory activities of anthocyanins and their aglycon, cyanidin, from tart cherries. J. Nat. Prod. 1999, 62, 294-296.

53. Mulabagal, V.; Lang, G.A.; DeWitt, D.L.; Dalavoy, S.S.; Nair, M.G. Anthocyanin content, lipid peroxidation and cyclooxygenase enzyme inhibitory activities of sweet and sour cherries. J. Agric. Food Chem. 2009, 57, 1239-1246.

54. Tall, J.M.; Seeram, N.P.; Zhao, C.; Nair, M.G.; Meyer, R.A.; Raja, S.N. Tart cherry anthocyanins suppress inflammation-induced pain behavior in rat. Behav. Brain Res. 2004, 153, 181-188.

55. Blau, L.W. Cherry diet control for gout and arthritis. Tex. Rep. Biol. Med. 1950, 8, 309-311.

56. Howatson, G.; McHugh, M.P.; Hill, J.A.; Brouner, J.; Jewell, A.P.; van Someren, K.A.; Shave, R.E.; Howatson, S.A. Influence of tart cherry juice on indices of recovery following marathon running. Scand. J. Med. Sci. Sports 2009, doi:10.1111/j.1600-0838.2009.01005.x.

57. Connolly, D.A.; McHugh, M.P.; Padilla-Zakour, O.I.; Carlson, L.; Sayers, S.P. Efficacy of a tart cherry juice blend in preventing the symptoms of muscle damage. Br. J. Sports Med. 2006, 40, 679-683. 
58. Kuehl, K.S.; Perrier, E.T.; Elliot, D.L.; Chesnutt, J.C. Efficacy of tart cherry juice in reducing muscle pain during running: A randomized controlled trial. JISSN 2010, 7, 17.

59. Seymour, E.M.; Singer, A.A.; Kirakosyan, A.; Urcuyo-Llanes, D.E.; Kaufman, P.B.; Bolling, S.F. Altered hyperlipidemia, hepatic steatosis, and hepatic peroxisome proliferator-activated receptors in rats with intake of tart cherry. J. Med. Food 2008, 11, 252-259.

60. Seymour, E.M.; Lewis, S.K.; Urcuyo-Llanes, D.E.; Tanone, I.I.; Kirakosyan, A.; Kaufman, P.B.; Bolling, S.F. Regular tart cherry intake alters abdominal adiposity, adipose gene transcription, and inflammation in obesity-prone rats fed a high fat diet. J. Med. Food 2009, 12, 935-942.

61. Wang, L.S.; Stoner, G.D. Anthocyanins and their role in cancer prevention. Cancer Lett. 2008, 269, 281-290.

62. Kang, S.Y.; Seeram, N.P.; Nair, M.G.; Bourquin, L.D. Tart cherry anthocyanins inhibit tumor development in $\mathrm{Apc}(\mathrm{Min})$ mice and reduce proliferation of human colon cancer cells. Cancer Lett. 2003,194, 13-19.

63. Bobe, G.; Wang, B.; Seeram, N.P.; Nair, M.G.; Bourquin, L.D. Dietary anthocyanin-rich tart cherry extract inhibits intestinal tumorigenesis in APC(Min) mice fed suboptimal levels of sulindac. J. Agric. Food Chem. 2006, 54, 9322-9328.

Sample Availability: Not Available.

(C) 2010 by the authors; licensee MDPI, Basel, Switzerland. This article is an open access article distributed under the terms and conditions of the Creative Commons Attribution license (http://creativecommons.org/licenses/by/3.0/). 